haben. Dns Bưd verdient nuđ in Sühdeutfijland Berbreitung, namenniक für foldje \$ribatmaldbefizer, welde ifre Baldungen jelbif bewirtbjdaften, vier Durd einen verftandigen $\mathfrak{B a l d g u ̈ t e r ~ b e s ~}$ handeln laffen.

Drua und Sapier find qut, einige Şolzfonitte fönnten beffer fein, ofge Das jebow Die Deutliđfeit nothgelitten hat.

Donaueftingen, Robember 1866.

Roth.

\title{
№. 5.
}

Serrn \$etermannz Jagobuબ. Bierter Theil. Sfizen und

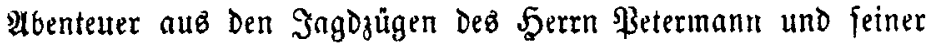

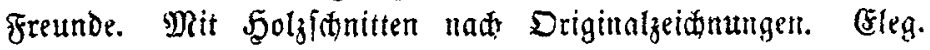
fart. Breis 1 Thlr. Mlündyen $\mathfrak{B e r l a g ~ y o n ~ B r a u n ~ u n d ~ S d j n e i d e r . ~}$

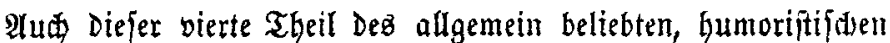

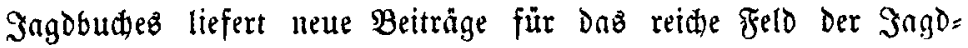
abentener. SBie die früberen Bände bietct auth diejer Durd feine

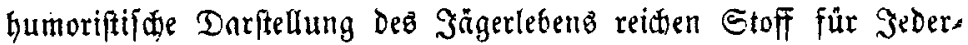
mann, und wiro für ieden $\mathfrak{B e r e f g r e r}$ des edten $\mathfrak{B a i b w e r f z ~ e i n ~ u n = ~}$

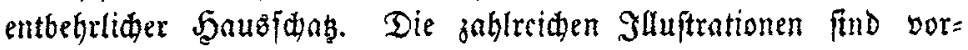
trefflid gelungen.

他. v. ש.

\section{Bitte.}

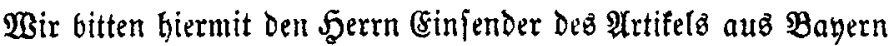

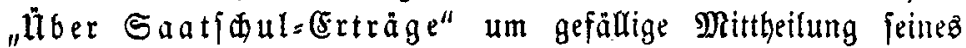
Bohnortz und Titelë, weil wir fonft die fraglide Albhandlung nicht aufnehmen fönnen.

Die Redaction.

Berautwortlider Sebacteur: Dr. Fr. Baur, Brofelfor an ber Mtabemie 5obeng̨eim. Druat uno Şerlą von $G$. Bdmeizerbart it Stuttgart. 